Bond University

Research Repository

\title{
Tattoos do not affect exercise-induced localised sweat rate or sodium concentration
}

Rogers, Ethan; Irwin, Christopher; McCartney, Danielle; Cox, Gregory R.; Desbrow, Ben

Published in:

Journal of Science and Medicine in Sport

DOI:

10.1016/j.jsams.2019.06.004

\section{Licence:}

CC BY-NC-ND

Link to output in Bond University research repository.

Recommended citation(APA):

Rogers, E., Irwin, C., McCartney, D., Cox, G. R., \& Desbrow, B. (2019). Tattoos do not affect exercise-induced localised sweat rate or sodium concentration. Journal of Science and Medicine in Sport, 22(11), 1249-1253. https://doi.org/10.1016/j.jsams.2019.06.004

\footnotetext{
General rights

Copyright and moral rights for the publications made accessible in the public portal are retained by the authors and/or other copyright owners and it is a condition of accessing publications that users recognise and abide by the legal requirements associated with these rights.
}

For more information, or if you believe that this document breaches copyright, please contact the Bond University research repository coordinator. 


\section{Abstract}

2 OBJECTIVES: Skin tattoos have been shown to reduce localised sweat rate and increase sweat

3 sodium concentration $\left(\left[\mathrm{Na}^{+}\right]\right)$when sweating is artificially stimulated. This study investigated

4 whether similar responses are observed with exercise-induced sweating. DESIGN: Unblinded,

5 within-participant control, single trial. METHODS: Twenty-two healthy individuals $(25.1 \pm 4.8$

$6 \mathrm{y}($ Mean $\pm \mathrm{SD}), 14$ males) with a unilateral tattoo $\geq 11.4 \mathrm{~cm}^{2}$ in size, $\geq 2$ months in age, and

7 shaded $\geq 50 \%$ participated in this investigation. Participants undertook 20 min of intermittent

8 cycling (4 x 5 min intervals) on a stationary ergometer in a controlled environment

$9 \quad\left(24.6 \pm 1.1^{\circ} \mathrm{C} ; 64 \pm 6 \% \mathrm{RH}\right)$. Resultant sweat was collected into absorbent patches applied at two

10 pairs of contralateral skin sites (pair 1: Tattoo vs. Non-Tattoo; pair 2: Control 1 vs. Control 2

11 (both non-tattooed)), for determination of sweat rate and sweat $\left[\mathrm{Na}^{+}\right]$. Paired samples $t$-tests

12 were used to determine differences between contralateral sites. RESULTS: Tattoo vs. Non-

13 Tattoo: Neither sweat rate (Mean \pm SD: $0.92 \pm 0.37$ vs $0.94 \pm 0.43 \mathrm{mg} \cdot \mathrm{cm}^{-2} \cdot \mathrm{min}^{-1}$, respectively; $14 p=.693)$ nor sweat $\left[\mathrm{Na}^{+}\right]\left(\right.$Median(IQR): 37(32-52) vs $37(31-45) \mathrm{mM} \cdot \mathrm{L}^{-1}$, respectively; $15 p=.827)$ differed. Control 1 vs. Control 2: Neither sweat rate (Mean \pm SD: $1.19 \pm 0.53$ vs $161.19 \pm 0.53 \mathrm{mg} \cdot \mathrm{cm}^{-2} \cdot \mathrm{min}^{-1}$, respectively; $\left.p=.917\right)$ nor sweat $\left[\mathrm{Na}^{+}\right]($Median(IQR): $29(26-41) \mathrm{vs}$ $1731(25-43) \mathrm{mM} \cdot \mathrm{L}^{-1}$, respectively; $\left.p=.147\right)$ differed. The non-significant differences for sweat rate and $\left[\mathrm{Na}^{+}\right]$between Tattoo vs. Non-Tattoo were inside the range of the within participant variability (sweat rate $\mathrm{CVi}=5.4 \%$; sweat $\left[\mathrm{Na}^{+}\right] \mathrm{CVi}=4.4 \%$ ). CONCLUSION: Skin tattoos do not appear to alter the rate or $\left[\mathrm{Na}^{+}\right]$of exercise-induced sweating. The influence of skin tattoos on localised sweat responses may have previously been over-estimated.

22 Key words: eccrine gland, thermoregulation, physical activity, fluid loss 


\subsection{Introduction}

Sweating is a crucial thermoregulatory mechanism in humans due to its facilitation of evaporative heat loss ${ }^{1}$. In response to exercise-induced heat production, eccrine sweat glands can produce whole body sweat rates up to $3 \mathrm{~L} \cdot \mathrm{h}^{-12}$, with sodium concentrations $\left(\left[\mathrm{Na}^{+}\right]\right)$between 15 to $120 \mathrm{mM} \cdot \mathrm{L}^{-1} 3,4$. Factors that compromise the function of the sweat gland, therefore, have the potential to impair thermoregulation during exercise.

Skin tattooing involves the deposition of ink into the skin via repeated microneedle penetration and has the potential to compromise eccrine sweat gland function, and consequently thermoregulation ${ }^{5}$. Given that tattoos are common, $(\sim 10 \%$ of populations in some countries (e.g. France, Finland and Australia) ${ }^{6}$ ), particularly, among physically active individuals (e.g. athletes and military personnel ${ }^{7}$ ), it is surprising that only two published studies ( 25 year apart) have explored the effect of tattoos on sweat responses ${ }^{5,8}$. The earliest of these, a case report $(n=1)$, described a $\sim 50 \%$ reduction in sweat rate responses to passive heat exposure. The recent investigation compared sweat samples taken from tattooed and nontattooed skin of 10 participants, following electrochemical sweat gland stimulation (pilocarpine iontophoresis) using a commercial sweat collection system (Macroduct ${ }^{\circledR}$, Wescor, Logan, UT). Again, results indicated tattooed skin had significantly compromised sweat gland function, with $\sim 50 \%$ reduced sweat rate (Non-tattooed skin $=0.35 \pm 0.25$ vs Tattooed skin $0.18 \pm 0.15$ $\mathrm{mg} \cdot \mathrm{cm}^{-2} \cdot \mathrm{min}^{-1}$ ) and increased $\left[\mathrm{Na}^{+}\right]$by $\sim 35 \%$ (Non-tattooed $=42.6 \pm 15.2$ vs Tattooed $=$ 69.1 $\left.\pm 28.9 \mathrm{mM} \cdot \mathrm{L}^{-1}\right)$, implicating the gland's distal tubule function ${ }^{9}$. These effects appeared independent of the tattoo's age (range 0.2-4 years), suggesting that skin tattooing may immediately impair regional thermoregulatory responses, and that these impairments are unlikely to resolve over time.

To date, no study has explored if skin tattoos influence exercise-induced sweating beyond the typical contralateral variation observed between two non-tattooed skin regions ${ }^{10}$. This is important, as sweat rates are considerably larger (up to $1.2 \mathrm{mg} \cdot \mathrm{cm}^{-2} \cdot \mathrm{min}^{-1}{ }^{3}$ ) than those 
observed during artificial sweat stimulation, and the thermoregulatory load associated with exercise triggers a cascade of neural and physiological responses that determine the sweating response ${ }^{1}$.

Therefore, the aim of this study was to explore the effect of skin tattoos on exerciseinduced sweat responses. Specifically, we endeavoured to understand if the presence of a tattoo compromised exercise-induced sweat response beyond the normal variation observed between contralateral non-tattooed sites. We hypothesised that sweat samples taken from tattooed skin would demonstrate compromised function (i.e. reduced sweat rates and increased $\left[\mathrm{Na}^{+}\right]$) compared to contralateral non-tattooed skin samples, irrespective of the age of the tattoo, in keeping with previous reports using artificial sweat stimulation. Furthermore, we anticipated that this variation would be greater than the typical variation observed between samples collected from two contralateral non-tattooed sites within individuals.

\subsection{Methods}

Twenty-two healthy volunteers $(14 \mathrm{M} / 8 \mathrm{~F}, \mathrm{ht}=176 \pm 9 \mathrm{~cm}$, body weight $=75 \pm 13 \mathrm{~kg})$ participated in this investigation involving a single laboratory visit. Individuals were eligible to participate if they met the following criteria: 1) aged between 18 and 45 years, 2) had a unilateral tattoo that was $\geq 2$ months old, $\geq 11.4 \mathrm{~cm}^{2}$ in size, and $\geq 50 \%$ shaded, and 3 ) deemed medically safe to undertake aerobic exercise. Table 1 describes participant and tattoo characteristics. Tattoos were categorised as 'Dense' if $>90 \%$ of the sample area was considered shaded $(n=14)$, or 'Partial' if shading covered 50 to $90 \%$ of the sample area $(n=8)$ (based on visual inspection). All participants provided written informed consent prior to commencing the study. All data were collected in the summer months (January-March). This investigation was approved by the XXXX (removed for blinding) University Human Research Ethics Committee (Ref No. 2017/955). 
sample for the determination of urine specific gravity $\left(\mathrm{U}_{\mathrm{SG}}\right)$ and a baseline nude body weight measure to allow for subsequent determination of whole body fluid loss. If $U_{S G}$ was $\geq 1.024$ $(n=1)$, indicating likely dehydration ${ }^{11}$, participants were asked to consume a bolus of water ( $\sim 400 \mathrm{~mL}$ ) prior to providing a second $\mathrm{U}_{\mathrm{SG}}$ measure $\sim 30$ minutes later.

Following the hydration measures, the skin of participants was inspected to identify the most suitable sample sites. The most densely shaded tattoo site (Tattoo) with a non-tattooed contralateral (Non-tattoo) area was identified. A direct distance (Lufkin ${ }^{\circledR} 2 \mathrm{~m}$ metal tape) to the nearest prominent anatomical landmark was used as a reference point to identify the appropriate contralateral site. For the control sites (Control $1 \& 2$ ), priority was given to a forearm location, $\sim 10 \mathrm{~cm}$ from the wrist flexion crease, except when this area was tattooed. Once identified all sites were cleaned with ethanol, followed by distilled water, and thoroughly dried. Pilot testing of the Macroduct ${ }^{\circledR}$ sweat collection system proved unreliable in our exercise-induced sweating context. Hence, a more common exercise-sweat collection protocol was employed ${ }^{10}$; the application of pre-weighed (HT-120, A\&D Company, Japan, Precision $=$ $0.01 \mathrm{~g})$, sterile absorbent patches (Tegaderm ${ }^{\mathrm{TM}}+\operatorname{Pad}(5 \mathrm{~cm} \times 7 \mathrm{~cm}), 3 \mathrm{M}$ Deutschland $\mathrm{GmbH}$, Germany, which contain an absorbance area of $2.75 \mathrm{~cm} \mathrm{x} 4.16 \mathrm{~cm}\left(11.445 \mathrm{~cm}^{2}\right)$, with a maximum capacity $1.34 \mathrm{~g}$. The remaining area is comprised of a non-absorbent adhesive film). The use of absorbent patches has been shown to reflect ventilated capsule methods for measuring local sweat rates with limits of detection of $\left(\sim 0.12 \mathrm{mg} \cdot \mathrm{cm}^{-2} \cdot \mathrm{min}^{-1}\right)$ suitable for the expected changes in exercise-induced sweating ${ }^{12}$. Patches at each contralateral skin site were applied simultaneously, shortly (i.e. $<5 \mathrm{~min}$ ) before commencing exercise.

To induce sweating, participants completed $4 \times 5$ min intervals (with 1 min rest between each) on an electronically braked cycle ergometer (Lode Excalibur Sport; Lode BV, Groningen, the Netherlands). The timed cycling began at a fixed power output intended to elicit a 'hard' rating of perceived exertion (RPE $\sim 15^{13}$ ). Heart rate (Suunto Ambit, Finland) and RPE 
were recorded at the end of each 5 min interval, at which point power output was adjusted to suit individual participant responses.

Following exercise, a short period of rest ( 3-5 min) was undertaken to ensure the patches absorbed any sweat resulting from the residual heat load. Subsequently, the time from exercise commencement was recorded, and the patches were removed and weighed for determination of sweat rate using the following formula:

Sweat rate $\left(\mathrm{mg} \cdot \mathrm{cm}^{-2} \cdot \mathrm{min}^{-1}\right)=\frac{(\text { Post-exercise patch }(\mathrm{mg})-\text { Pre-exercise patch }(\mathrm{mg}))}{11.445 \mathrm{~cm}^{-2}} \div$ Collection period $\left(\mathrm{min}^{-1}\right)$

Used patches were then placed into sterile tubes and centrifuged at $3400 \mathrm{rpm}$ for $5 \mathrm{~min}$ to extract a sweat sample for subsequent $\left[\mathrm{Na}^{+}\right]$analysis using a calibrated sodium ion meter (LAQUA-Twin B-722, Horiba, Japan), previously validated for sweat $\left[\mathrm{Na}^{+}\right]$analysis ${ }^{14}$. All measures were performed in duplicate. Finally, participants towel dried before providing a nude body weight for the determination of whole body fluid loss.

Statistical procedures were performed using IBM SPSS, Version 25.0. All measures were examined for normality (Shapiro-Wilk test). When normally distributed, differences in mean data was analysed using parametric tests (e.g. paired-samples $t$-tests). When assumptions of normality were violated, differences were assessed using nonparametric measures (e.g.

118 Wilcoxon signed rank test). The co-efficient of variation (CV) across the control sweat sites was considered as analytical $(\mathrm{CVa})$, within $(\mathrm{CVi})$, and between $(\mathrm{CVg})$ participant variation using traditional methods ${ }^{15}$. The $\mathrm{CV}$ a of the sodium analyser has been previously determined $(3.7 \%)^{16}$. The relationship between tattoo age and change in sweat responses between tattooed and non-tattooed skin was assessed using the correlation coefficient. All normally distributed data are presented as means and standard deviations (Mean \pm SD), while skewed data are presented as medians and interquartile ranges (Median(IQR)). Statistical significance was accepted as $\mathrm{p}<0.05$. 


\subsection{Results}

127 Throughout exercise, participants reported a mean RPE of $14 \pm 1.6$ (average HR = $128165 \pm 22 \mathrm{bpm}$, av. workload $=135 \pm 38($ range $=65-250) \mathrm{W})$. The exercise task resulted in a mean body weight loss of $0.55 \pm 0.33 \%$ from the participant's initial nude body weight, which equated to an average sweat rate of $1.2 \pm 0.6 \mathrm{~L} \cdot \mathrm{h}^{-1}$. The mean sweat rate from contralateral control sites was not significantly different (Control $1=1.19 \pm 0.53$ vs. Control $2=1.19 \pm 0.53$ $\mathrm{mg} \cdot \mathrm{cm}^{-2} \cdot \mathrm{min}^{-1}$, respectively, $\left.\mathrm{t}(21)=-0.106, \mathrm{p}=0.917\right)$. Similarly, the median $\left[\mathrm{Na}^{+}\right]$from the control sites was not significantly different (Control $1=29(26-41)$ vs. Control $2=31(25-43)$ $\left.\mathrm{mM} \cdot \mathrm{L}^{-1}, \mathrm{Z}=-1.450, \mathrm{p}=0.147\right)$. The $\mathrm{CVi}$ of participants' sweat rates and $\left[\mathrm{Na}^{+}\right]$across these sites was $5.4 \%$ and $3.8 \%$, respectively. The $\mathrm{CVg}$ of participants' sweat rates and $\left[\mathrm{Na}^{+}\right]$across forearm sites only $(n=16)$ was $47 \%$ and $43 \%$, respectively. tattooed skin was not significantly different from contralateral non-tattooed skin (Tattoo $=$ $0.92 \pm 0.37$ vs. Non-tattoo $\left.=0.94 \pm 0.43 \mathrm{mg} \cdot \mathrm{cm}^{-2} \cdot \mathrm{min}^{-1}, \mathrm{t}(21)=-.400, \mathrm{p}=0.693\right)$. Furthermore, when considering only densely tattooed skin $(n=14)$, sweat rates were not different from the corresponding non-tattooed skin (Dense tattoo $=0.97 \pm 0.44$ vs. Non-Tattoo $=0.97 \pm 0.50$ $\left.\mathrm{mg} \cdot \mathrm{cm}^{-2} \cdot \mathrm{min}^{-1}, \mathrm{t}(13)=0.164, \mathrm{p}=0.872\right)$.

Participant's individual sweat $\left[\mathrm{Na}^{+}\right]$are displayed in Figure 2. The median sweat $\left[\mathrm{Na}^{+}\right]$

144 from tattooed skin was not significantly different from contralateral non-tattooed skin (Tattoo $145=37(32-52) \mathrm{vs}$ Non-tattoo $\left.=37(31-45) \mathrm{mM} \cdot \mathrm{L}^{-1}, \mathrm{Z}=-0.218, \mathrm{p}=0.827\right)$. When considering only 146 densely tattooed skin, sweat $\left[\mathrm{Na}^{+}\right]$was not significantly different from non-tattooed skin $147\left(\right.$ Dense tattoo $=37(30-39)$ vs Non-tattoo $\left.=36(31-39) \mathrm{mM} \cdot \mathrm{L}^{-1}, \mathrm{Z}=-0.051, \mathrm{p}=0.959\right)$.

No significant correlation was observed between tattoo age and percentage change in sweat rate $(r=0.007, \mathrm{p}=0.975)$ or sweat $\left[\mathrm{Na}^{+}\right](r=-0.141, \mathrm{p}=0.532)$ (Supplementary Figure). 

exercise employing a sweat patch collection method. Contrary to our hypothesis, results from the present study suggest that sweat rate and $\left[\mathrm{Na}^{+}\right]$do not differ between tattooed skin and contralateral non-tattooed skin. Indeed, any variance observed between sites was within the typical contralateral (non-tattooed skin) variability of individuals. Thus, tattoos are unlikely to influence sweat-mediated thermoregulation in exercising individuals.

Two previous studies have raised concerns that skin tattoos may negatively influence sweat-mediated thermoregulation ${ }^{5,8}$. The most recent (and more rigorous) of these investigations employed artificial sweat gland stimulation and indicated that tattoos substantially reduced sweat rate (Cohen's $d=0.79)$ and increased sweat $\left[\mathrm{Na}^{+}\right](\mathrm{Cohen}$ 's $d=1.01$ ). Given that these responses were independent of tattoo age, and were consistent across all participants, the authors attributed the compromised sweat response to damage to, or blockage of, the sweat glands caused by the repeated needling process involved in tattooing. Indeed, fractional micro-needling radiofrequency treatment, (a procedure similar to tattooing with concurrent thermal energy delivery), has recently been described as an effective treatment modality for axillary osmidrosis ${ }^{17}$. Collectively, this supports the logic of a probable attenuation of sweating response in tattooed skin during exercise.

The current results are in contrast to our hypothesis; failing to demonstrate a tattoomediated impaired sweating response local to the site of the tattoo. Moreover, no effect was observed when the analysis was performed exclusively on the most densely shaded tattoos (i.e. involving the greatest number of skin penetrations and ink deposition). The disparity in observations between studies may, in part, be due to a number of methodological differences. For instance, pilocarpine iontophoresis ${ }^{5}$ induces sweating via local cholinergic stimulation, whereas exercise-induced sweating triggers a combination of local and central mediators ${ }^{18}$, which results in considerably ( $\sim 3-5$ fold) higher sweat rates ${ }^{3}$. Furthermore, the current investigation employed absorbent patches to collect sweat, while a sodium ion-selective 
177 electrode analyser was used to assess $\left[\mathrm{Na}^{+}\right]$. These approaches were employed based on pilot 178 testing and recommendations as preferred methods of sweat collection during exercise due to 179 their accuracy, validity and practicality ${ }^{10,12,14}$. For example, the current method resulted in 180 sweat volumes comfortably within the absorbance capacity of the patch (e.g. maximum sweat rate from any individual site $=2.65 \mathrm{mg} / \mathrm{cm}^{2} / \mathrm{min}$, or $57 \%$ of the $1.34 \mathrm{~g}$ capacity (based on $\sim 25$ min exposure). The impact of these methodological differences was not directly investigated as the sweat collection system used in Luetkemeier et al ${ }^{5}$ proved unreliable in our exercising conditions.

Results from the current investigation do not indicate a need for altered cooling, and/or nutritional (i.e. fluid administration) advice to tattooed individuals undertaking exercise. That said, it is important to acknowledge that the studies to date (including this investigation) have monitored typically small tattoos in locations not necessarily associated with anatomical regions known to have the largest sweat rates (e.g. head or back ${ }^{19}$ ). Future investigations should confirm the presence of localised anatomical and/or neurological changes associated with tattooing, in particular the impact of different tattooing techniques, equipment, materials

192 (inks), and reactions ${ }^{20}$ which may, in turn, influence sweat gland function. At present, it is unknown if large surface area tattoos, covering regions of high sweat rates, compromise skin 194 temperature and/or whole body thermoregulatory responses to standardised thermal loads (e.g. 195 sweating onset (via ventilated sweat capsule) or sudomotor responsiveness (via axon reflex 196 tests).

\subsection{Conclusion}

Overall, the present data indicate that tattooed skin was capable of rapidly producing sweat, without influencing $\mathrm{Na}^{+}$resorption, in response to variable metabolic heat loads. 
- Previous studies have raised concerns that tattoos impair sweating responses and therefore could expose individuals to greater risks of heat-related illnesses.

- Under the exercising and environmental conditions employed in this study, our data suggest that skin tattoos do not appear to alter the amount (rate) or sodium concentration (type) of sweat produced.

- The influence of skin tattoos on sweat responses to exercise may have previously been over-estimated. 
208 Conflict of Interest: The authors have no conflicts of interest to disclose and confirm the

209 data within is presented honestly and without fabrication, falsification, or inappropriate data 210 manipulation. 


\section{References}

212 1. Tan CL, Knight ZA. Regulation of Body Temperature by the Nervous System. Neuron.

2. Armstrong LE, Hubbard RW, Jones BH, Daniels JT. Preparing Alberto Salazar for the Heat of the 1984 Olympic Marathon. The Physician and sportsmedicine. 1986;14(3):73-81.

3. Buono MJ, Ball KD, Kolkhorst FW. Sodium ion concentration vs. sweat rate relationship in humans. J Appl Physiol (1985). 2007;103(3):990-994.

4. Bulmer MG, Forwell GD. The concentration of sodium in thermal sweat. J Physiol. 1956;132(1):115-122.

5. Luetkemeier MJ, Hanisko JM, Aho KM. Skin Tattoos Alter Sweat Rate and Na+ Concentration. Med Sci Sports Exerc. 2017;49(7):1432-1436.

6. Serup J, Kluger N, Baumler W. Epidemiology of tattoos in industrialized countries. Tattooed Skin and Health. 2015;48:6-20.

7. Armstrong ML, Murphy KP, Sallee A, Watson MG. Tattooed Army soldiers: examining the incidence, behavior, and risk. Mil Med. 2000;165(2):135-141.

8. Cotton DW, Kuypers BR. Thermal induced sweating in tattooed skin. Dermatologica. 1970;141(3):252-254.

9. Sato K, Kang WH, Saga K, Sato KT. Biology of sweat glands and their disorders. I. Normal sweat gland function. J Am Acad Dermatol. 1989;20(4):537-563.

10. Baker LB. Sweating Rate and Sweat Sodium Concentration in Athletes: A Review of Methodology and Intra/Interindividual Variability. Sports Med. 2017;47(Suppl 1):111128.

11. Armstrong LE, Pumerantz AC, Fiala KA, et al. Human hydration indices: acute and longitudinal reference values. Int J Sport Nutr Exerc Metab. 2010;20(2):145-153.

12. Morris NB, Cramer MN, Hodder SG, Havenith G, Jay O. A comparison between the technical absorbent and ventilated capsule methods for measuring local sweat rate. $J$ Appl Physiol (1985). 2013;114(6):816-823.

13. Borg GA. Perceived exertion: a note on "history" and methods. Med Sci Sports. 1973;5(2):90-93.

14. Goulet EDB, Baker LB. Sweat Sodium Concentration: Inter-Unit Variability of a Low Cost, Portable, and Battery Operated Sodium Analyzer. Int J Sport Nutr Exerc Metab. 2017;27(6):528-532.

15. Kenefick RW, Cheuvront SN, Elliott LD, Ely BR, Sawka MN. Biological and analytical variation of the human sweating response: implications for study design and analysis. American journal of physiology Regulatory, integrative and comparative physiology. 2012;302(2):R252-258.

16. Goulet ED, Dion T, Myette-Cote E. Validity and reliability of the Horiba C-122 compact sodium analyzer in sweat samples of athletes. Eur J Appl Physiol. 2012;112(10):34793485.

17. Lin L, Huo R, Bi J, Meng Z, Cao Y. Fractional microneedling radiofrequency treatment for axillary osmidrosis: A minimally invasive procedure. J Cosmet Dermatol. 2019;18(1):115-120.

18. Shibasaki M, Crandall CG. Mechanisms and controllers of eccrine sweating in humans. Front Biosci (Schol Ed). 2010;2:685-696.

19. Baker LB, Ungaro CT, Sopena BC, et al. Body map of regional vs. whole body sweating rate and sweat electrolyte concentrations in men and women during moderate exercise-heat stress. J Appl Physiol (1985). 2018;124(5):1304-1318. 
20. Kluger N. Self-reported tattoo reactions in a cohort of 448 French tattooists. International journal of dermatology. 2016;55(7):764-768. 


\section{Figure Captions}

263 Figure 1. Individual sweat rates $(\mathrm{n}=22)$ at different skin locations. Dashed lines with open circles

264 represent partially shaded tattoos. Includes Mean \pm SD (thick solid line).

265 Figure 2. Individual sweat sodium concentrations $\left[\mathrm{Na}^{+}\right](\mathrm{n}=22)$ at different skin locations. Dashed

266 lines with open circles represent partially shaded tattoos. Includes Median (IQR) (thick solid line).

267 Supplementary Figure. Correlations between tattoo age (y) and change in sweat responses

$268(\%)$ between tattooed and non-tattooed skin $(n=22)$. 